\title{
A bi-axial model for concrete under high-strain rate conditions
}

\author{
H.-G. Kwak \& H. Gang \\ Department of Civil and Environmental Engineering, KAIST, Korea
}

\begin{abstract}
In the context of the rising demand for reliability and safety in concrete subjected to blast or impact loading, understanding the bi-axial behavior of concrete under high-strain rate conditions is an issue of great significance in civil engineering. Since concrete is an anisotropic material, the dynamic bi-axial behavior of concrete should be considered when describing a concrete structure subjected blast or impact loading. Concrete subjected to bi-axial high-strain rates loading shows quite different behavior from that under un-axial static loads, because of confinement effect and strain rate effect. Although several dynamic bi-axial models for concrete have been proposed to describe the high-strain rate bi-axial behavior of concrete, it is difficult to reflect the coupled effect of the strain rate and lateral pressure reasonably. To solve this problem, this paper introduces a bi-axial model for concrete under high-strain rate conditions by combining the HJC (Holmquist-Johnson-Cook) model and the bi-axial model proposed by Yan. The proposed model takes into account the strain rate effect with the HJC model and the confining pressure effect with the Yan model independently. A failure envelop consists of the compression-compression region using the proposed model and the tension-tension region using CEB-FIP code. Furthermore, high-strain rate biaxial stress-strain curves for the compression-compression region determined by the proposed model are compared with experimental results, the HJC (Holmquist-Johnson-Cook) model and the K\&C (Karagozian \& Case) model to verify accuracy of the proposed model. The results indicate that the introduced model can effectively describe the bi-axial compressive behavior of concrete under high-strain rate conditions.

Keywords: high-strain rate concrete, bi-axial concrete model, strain rate effect, confining pressure effect.
\end{abstract}




\section{Introduction}

With the increasing need to ensure safety of concrete structures from explosions, which recently have occurred frequently, as well as against the risk of natural hazards such as tornados, various studies ranging from identification of dynamic material properties to analysis of structural responses under blast and impact loadings have been conducted. Concrete structures subjected to blast or impact loading present significantly different structural behaviour from that observed under static loading conditions. This difference is basically caused by the large deformation and pressure under dynamic loading accompanying high-strain rate deformation. Hence, confinement effect with respect to the pressure and effect of high-strain rate deformation that occurs during a short period of time must be taken into account to exactly describe the behavior of concrete structures subjected to blast or impact loading [1]. In this context, numerous studies, from the Marais experiment [2], which identified material properties of various materials with the SHPB (Split Hopkinson Pressure Bar) test, to research by Georgin and Reynouard [3], who carried out a numerical analysis for structures under impact loading, have been conducted. The obtained research results have been used in developing design codes such as the CEB-FIP model code [4] and also have been implemented into many commercialized programs including LSDYNA [5] and ABAQUS [6] to be used in tracing the nonlinear response of structures subjected to blast and impact loadings. Unfortunately, most research to date has been conducted in relation to uniaxial high-strain rate condition, partly because of the difficulties involved in multi-axial dynamic experiments for concrete. Bischoff and Perry [7] reviewed the test results of concrete in dynamic compressive loading. Malvar and Ross [8] summarised the test results of concrete in dynamic tensile loading. Bićanić and Zienkiewicz [9] generalised the dynamic behaviour of concrete based on the experimental results in uniaxial stress state and established the dynamic constitutive model. Recently, the HJC (Holmquist-Johnson-Cook) model [10], the K\&C (Karagozian \& Case) model [11] and the Yan and Lin model [12] have been proposed to describe effect of strain rate and pressure, however it is unable to reflect the coupled effect of strain rate and lateral pressure reasonably. To solve the problem, this paper introduces a bi-axial model for concrete under high-strain rate conditions by combining HJC (Holmquist-Johnson-Cook) model and the biaxial model proposed by Yan. The proposed model takes into account the strain rate effect with $\mathrm{HJC}$ model and the confining pressure effect with the Yan model independently. Furthermore, High-strain rate biaxial stress-strain curves for compression-compression region determined by the proposed model are compared with experimental results, the HJC (Holmquist-JohnsonCook) model and the $\mathrm{K} \& \mathrm{C}$ (Karagozian \& Case) model to verify accuracy of the proposed model. 


\section{High-strain rate bi-axial model for concrete}

\subsection{HJC (Holmquist-Johnson-Cook) model}

HJC model [10] is a computational constitutive model for concrete subjected to large strains, high-strain rate, and high pressure. Equation for HJC model is expressed in Eq. (1).

$$
\sigma^{*}=\left[A\left(1-D_{c}\right)+B P^{* N}\right]\left(1+C \ln \left(\dot{\varepsilon}^{*}\right)\right)
$$

where, $\mathrm{A}$ is the normalized cohesive strength, $\mathrm{B}$ is the normalized pressure hardening coefficient, $\mathrm{N}$ is the pressure hardening exponent, $\mathrm{C}$ is the strain rate coefficient, $\mathrm{D}$ is damage, $\sigma^{*}=\sigma / f_{c}$ is normalized stress (where $f_{c}$ is quasi-static uniaxial compressive strength), $P^{*}=P / f_{c}$ is normalized pressure (where $\mathrm{P}$ is the actual pressure), and $\dot{\varepsilon}^{*}=\dot{\varepsilon} / \dot{\varepsilon}_{0}$ is the dimensionless strain rate (where $\dot{\varepsilon}$ is the actual strain rate and $\dot{\varepsilon}_{0}$ is the reference strain rate). As shown in Fig. 1, when literature value is used for material constant $\mathrm{A}, \mathrm{B}, \mathrm{N}$, and $\mathrm{C}, \mathrm{HJC}$ model (strain rate: $272 / \mathrm{s}, 357 / \mathrm{s}, 460 / \mathrm{s}$ ) gives unsatisfactory agreement with experimental results. In this reason, this paper uses own value for material constants determined on the basis of SHPB (Split-Hopkinson Pressure Bar) test and triaxial compression test. SHPB (Split-Hopkinson Pressure Bar) test has been performed for starin rate $100 / \mathrm{s}-600 / \mathrm{s}$ and triaxial compression test has been performed for confinement pressure 4Mpa - 10Mpa. As shown in Fig. 2, own model construction program has been used for finding material constants $\mathrm{A}, \mathrm{B}, \mathrm{N}, \mathrm{C}$ on the basis of experimental results. As a results, Material constants which show good agreement with experimental stress-strain curve on the basis of least square method is $\mathrm{A}=0.698, \mathrm{~B}=2, \mathrm{~N}=1.3, \mathrm{C}=0.009$.

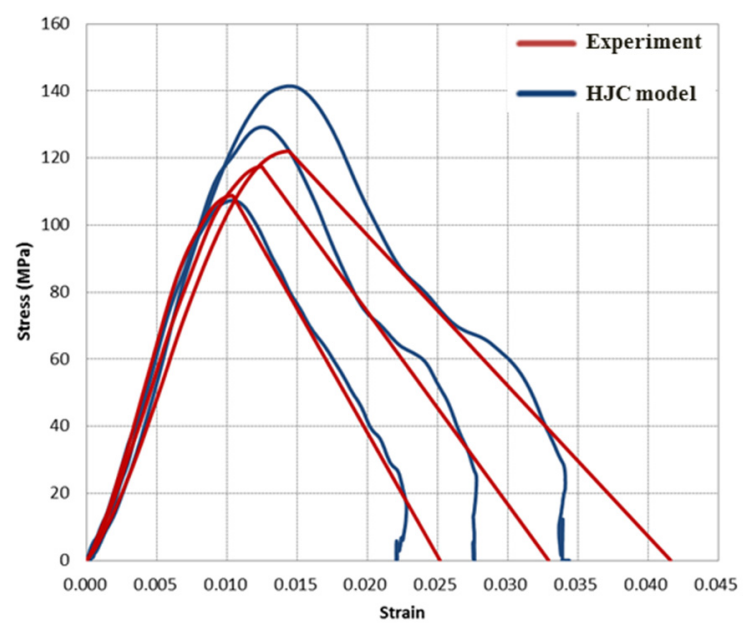

Figure 1: Comparison between the HJC model using literature value for material constant and experimental results. 


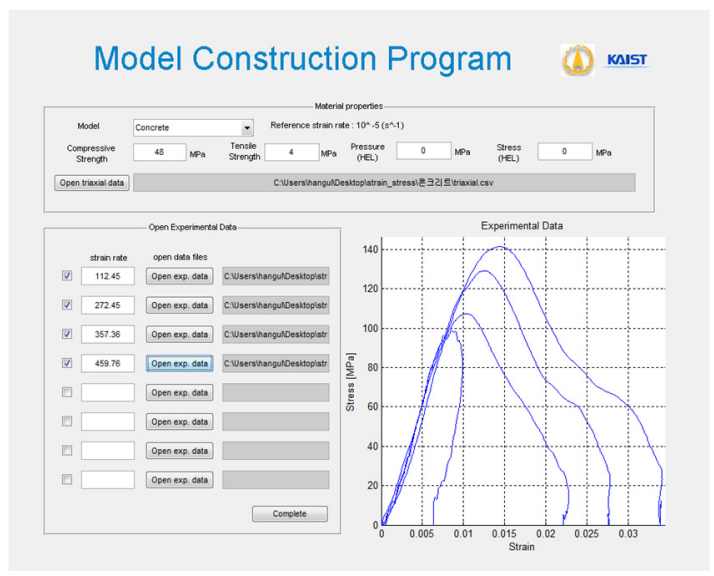

Figure 2: Model construction program.

As shown in Fig. 3, the HJC model shows satisfactory agreement with experimental results with own value for material constants. Since the HJC model have been used to account for strain rate effects in this paper, uniaxial compression strength calculated by the HJC model using $P^{*}=\frac{1}{3} \frac{\sigma}{f_{c}^{\prime}}$ in order to eliminate confinement effect is used in high-strain rate bi-axial model suggested in this paper.

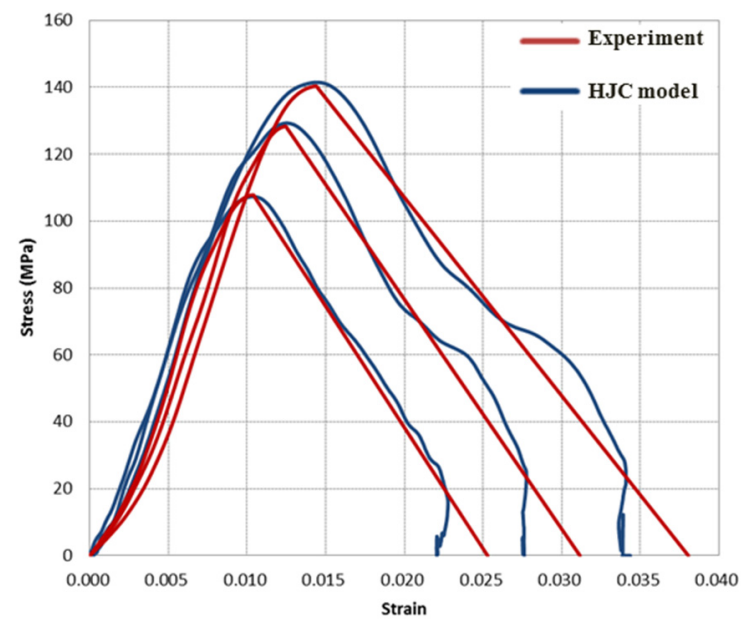

Figure 3: Comparison between the HJC model using own value for material constant and experimental results. 


\subsection{Biaxial model proposed by Yan}

Biaxial model proposed by Yan and Lin [12] takes account for both the effect of strain rate and the effect of stress ratio on the ultimate strength of concrete in biaxial stress states. Yan model is suggested as follows

$$
R(\alpha)=P_{1}+P_{2} \log \left(\frac{\dot{\varepsilon}}{\dot{\varepsilon}_{S}}\right)+\frac{P_{3}}{(1+\alpha)^{2}}+\frac{P_{4} \alpha}{(1+\alpha)^{2}}
$$

where $P_{1}, P_{2}, P_{3}$ and $P_{4}$ represent the parameters associated with material properties, $\alpha=\frac{\sigma_{2}}{\sigma_{1}}$ is the stress ratio, $\dot{\varepsilon}$ is the strain rate and $\dot{\varepsilon}_{s}$ is the quasi-static strain rate, its value being selected as $10^{-5} / \mathrm{s}$ in this paper. It is noted that Yan model takes into account the strain-rate effect and the confining pressure effect independently and thus it is unable to reflect the coupled effect of strain rate and lateral pressure reasonably [12]. Therefore, the Yan model is modified to eliminate strain rate effect in it by dividing $R(\alpha)$ with $R(0)$ in this paper. Modified Yan model has been used for high-strain rate bi-axial model suggested in this paper to account for lateral confinement effect of concrete.

\subsection{Proposal of high-strain rate bi-axial model for concrete}

High-strain rate bi-axial model for concrete is proposed by combining uniaxial strength calculated by the HJC model using own material constants and failure envelop of the modified Yan model. The proposed model takes into account the strain rate effect with The HJC model and the confining pressure effect with the Yan model independently. Failure envelop consists of compression-compression region using proposed model in Eq. (3), tension-tension region using CEB-FIP code [4] and compression-tension region using linear interpolation.

$$
f(\alpha)=\frac{R(\alpha)}{R(0)} \cdot\left[A+B\left(\frac{1}{3} \frac{\sigma}{f_{c}}\right)^{N}\right]\left[1+C \ln \left(\dot{\varepsilon}^{*}\right)\right]
$$

The proposed bi-axial failure envelop is visualized in Fig. 4. Strength of concrete, which takes account for both the strain rate effect and the confinement effect, is estimated with proposed failure envelop. The stress-strain curve is estimated with an algorithm (shown in Fig. 5) on the basis of strength calculated by the proposed failure envelop. 


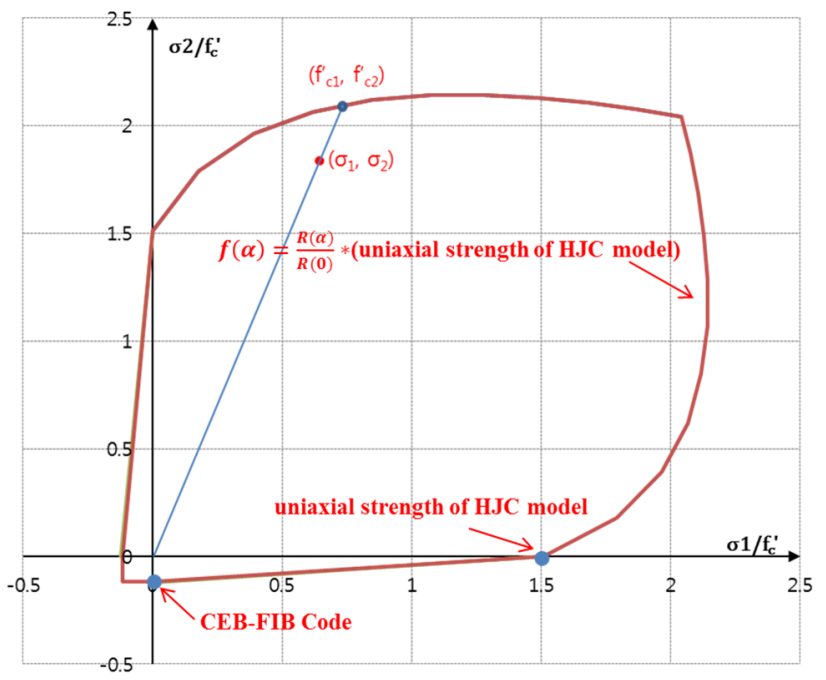

Figure 4: Proposed bi-axial high-strain rate model for concrete.

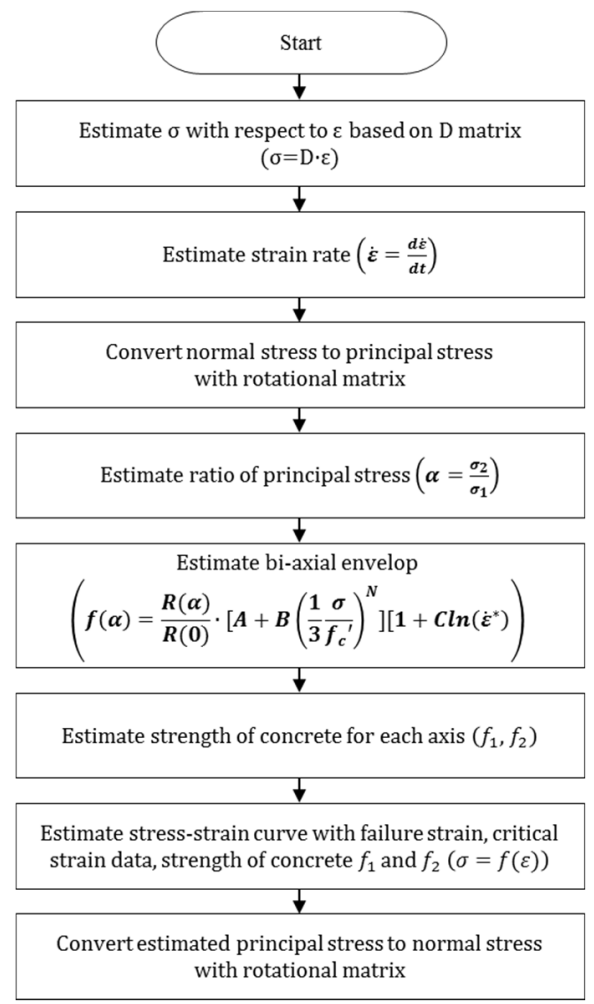

Figure 5: Proposed algorithm of bi-axial high-strain rate model for concrete. 


\section{Comparison with experimental results and preceding models}

Stress-strain curve for compression part suggested by proposed bi-axial model has been compared with experimental results [12], the HJC model [10] using literature value for material constants and $\mathrm{K} \& \mathrm{C}$ model [11] to testify the accuracy of the proposed bi-axial model. The strain rate varied from $10^{-5} / \mathrm{s}$ to $10^{-2} / \mathrm{s}$ and lateral pressure was maintained at a fixed proportion to the axial load, with the stress ratios of $0: 1,0.5: 1,1: 1$ respectively. Comparison is needed at higher strain rates in order to ensure the reliability of the proposed bi-axial model, but comparison at low strain rate was performed due to lack of experimental data. Comparison results are shown in Figs 6-8. In the case of stress ratio of $0: 1$, strain rate effect is only considered in stress-strain curve because it is in uniaxial compression condition. As shown in Fig. 6, the $\mathrm{K} \& \mathrm{C}$ model and proposed model show good agreement with experimental results, whereas the HJC model overestimates stress conditions.

Strain rate: $10^{-5} / \mathrm{s}$

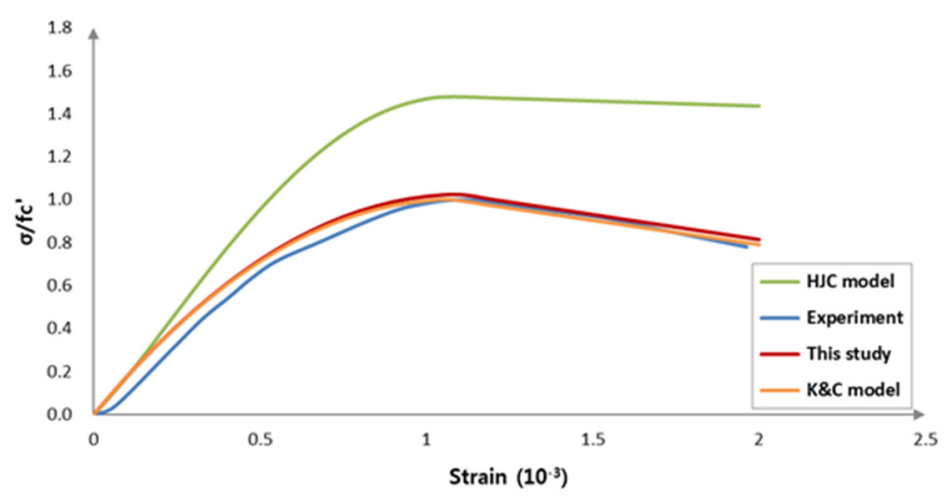

Strain rate: $10^{-4} / \mathrm{s}$

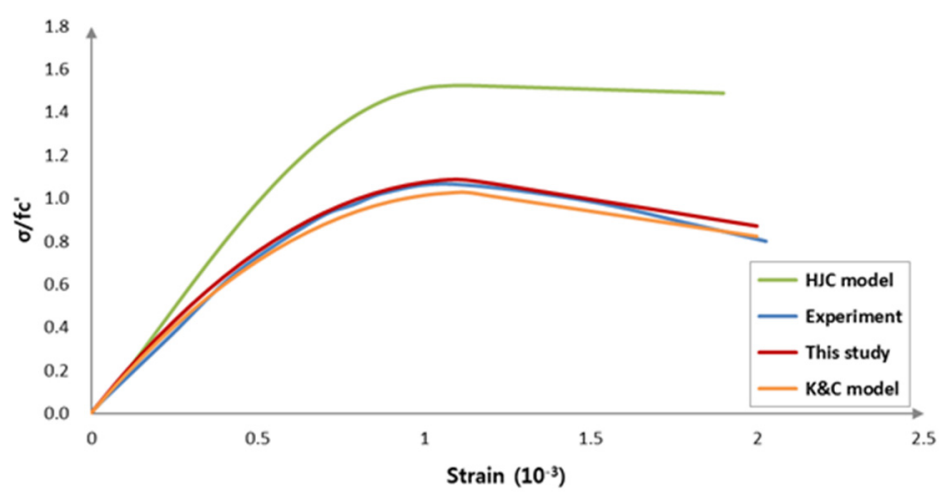

Figure 6: Stress-strain curve for a stress ratio of $0: 1$. 

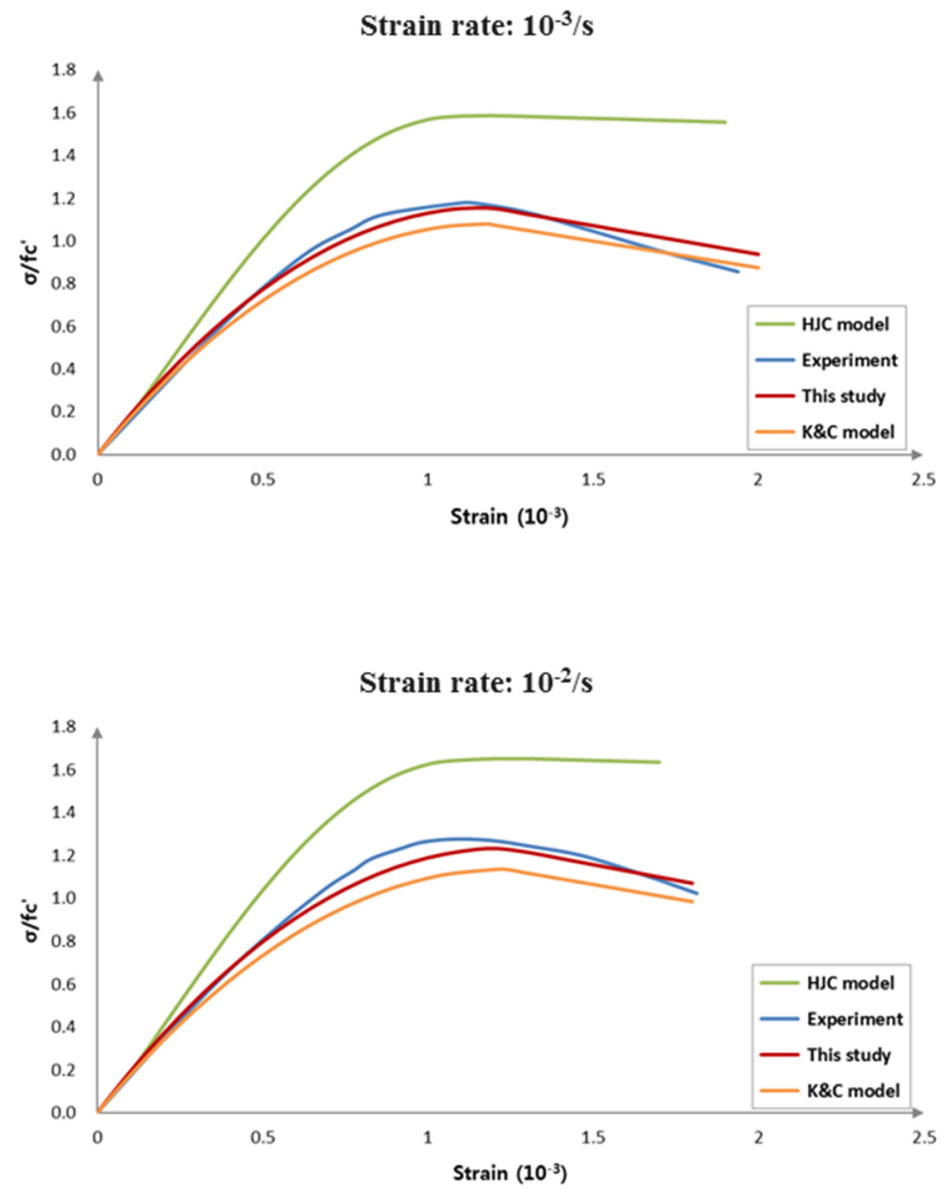

Figure 6: Continued.

In the case of a stress ratio of $0.5: 1$, the $\mathrm{K} \& \mathrm{C}$ model underestimates the stress condition and the proposed model shows good results. The HJC model seems to show good results, however it is not true. Stress in stress ratio 1:0.5 should be greater than that in stress ratio 1:1, but HJC shows greater stress condition in stress ratio of 1:1. 


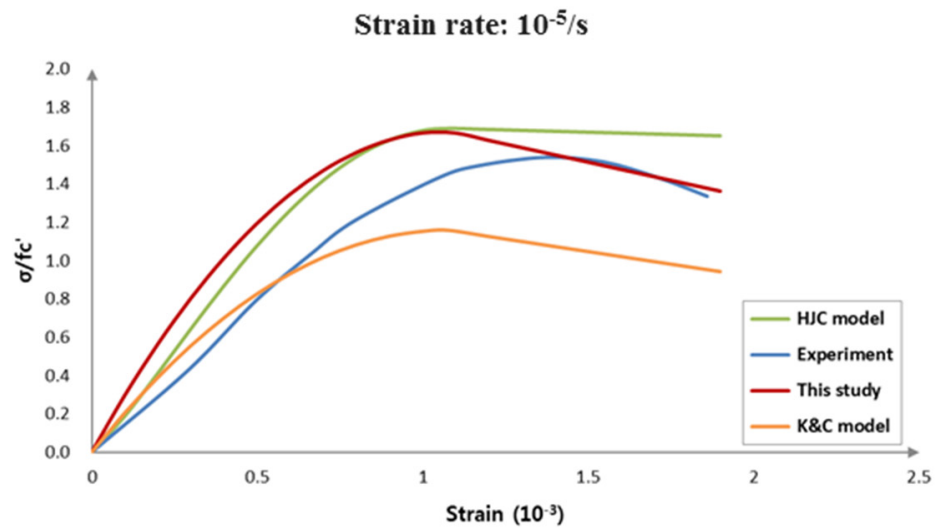

Strain rate: $10^{-4} / \mathrm{s}$

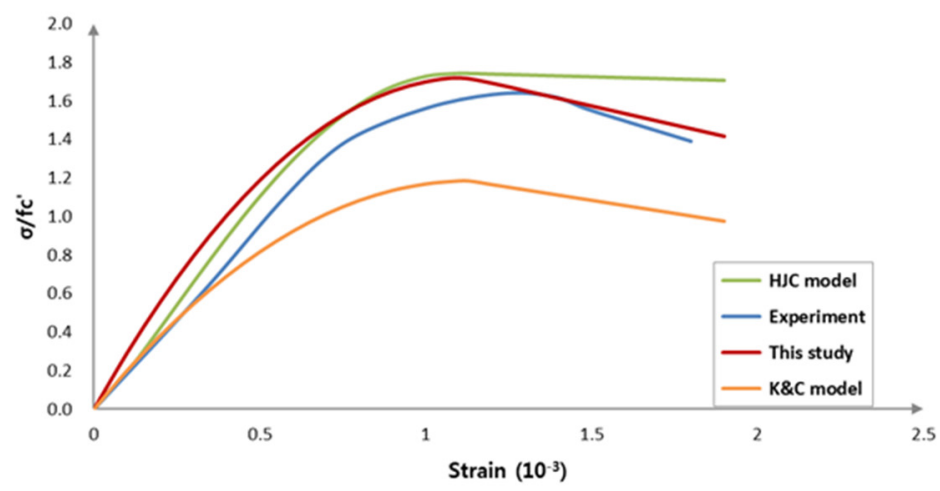

Strain rate: $10^{-3} / \mathrm{s}$

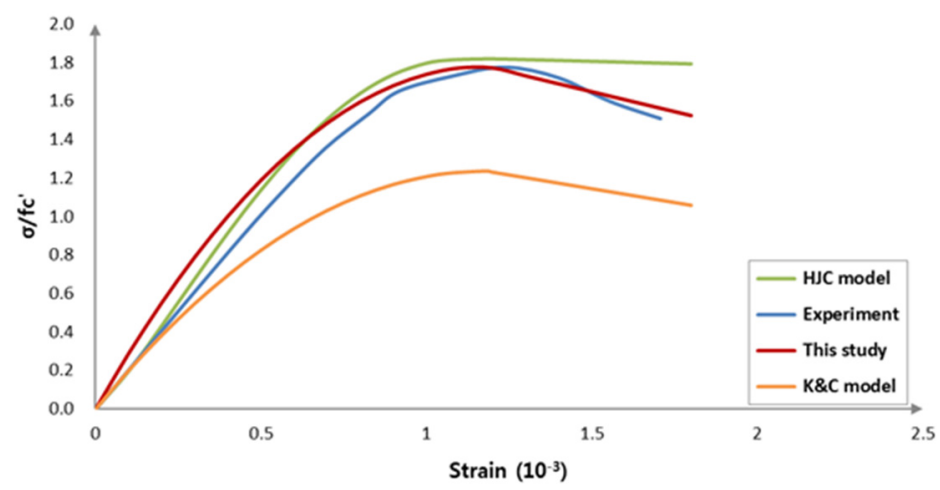

Figure 7: $\quad$ Stress-strain curve for a stress ratio of $0.5: 1$. 


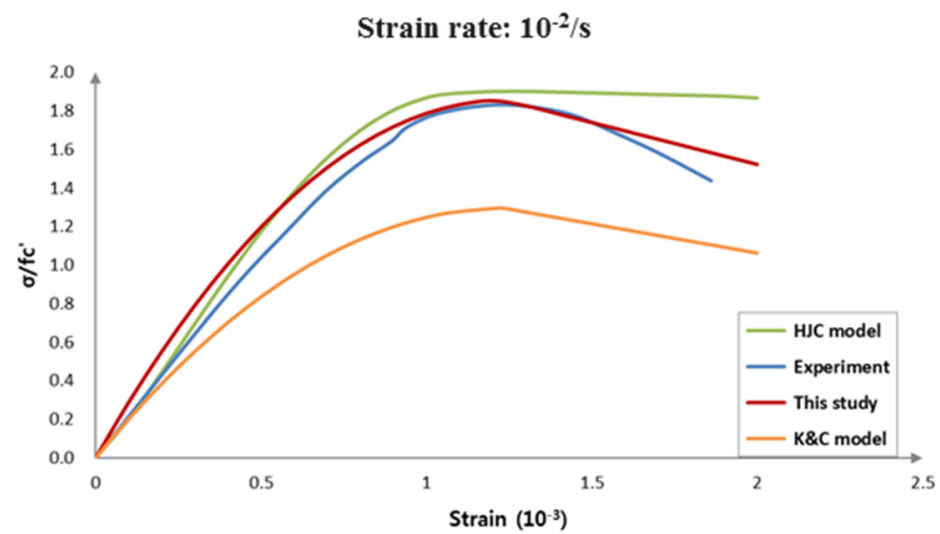

Figure 7: Continued.

Strain rate: $10^{-5} / \mathrm{s}$

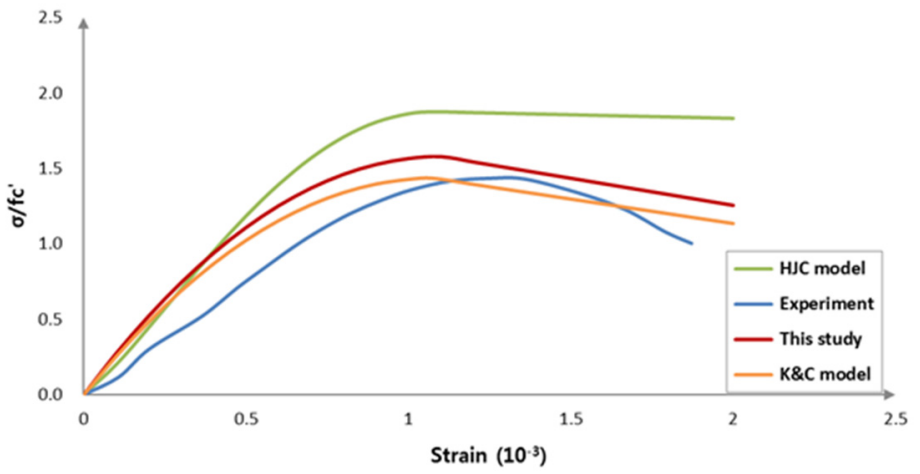

Strain rate: $10^{-4} / \mathrm{s}$

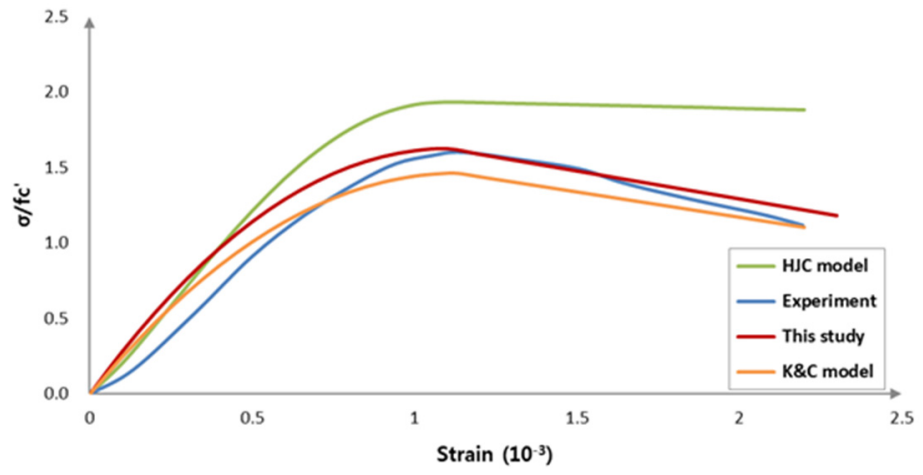

Figure 8: Stress-strain curve for a stress ratio of $1: 1$. 


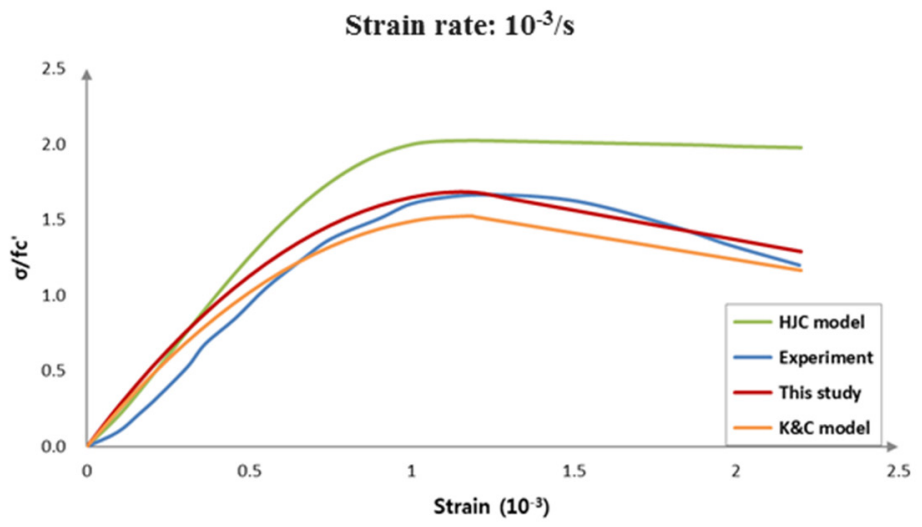

Strain rate: $10^{-2} / \mathrm{s}$

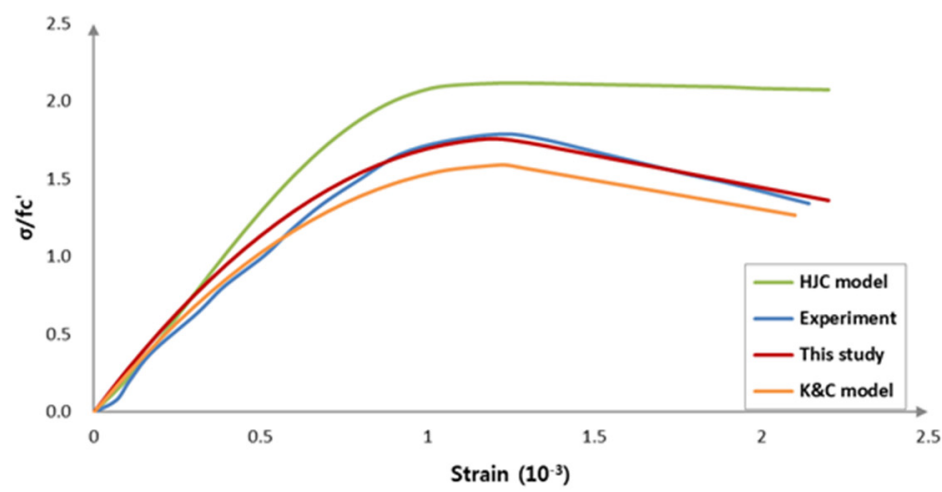

Figure 8: Continued.

In the case of a stress ratio of $1: 1$, the HJC model overestimates stress conditions and $\mathrm{K} \& \mathrm{C}$ model underestimates stress conditions. As a result, bi-axial model proposed in this paper can be used to describe compressive bi-axial behaviour of concrete under high-strain rate conditions.

\section{Conclusion}

This paper introduces a bi-axial model for concrete under high-strain rate conditions by combining HJC (Holmquist-Johnson-Cook) model and bi-axial model proposed by Yan. The Proposed model takes into account the strain rate effect with the HJC model and the confining pressure effect with Yan model independently. Furthermore, stress-strain curve for compression part suggested by proposed bi-axial model has been compared with experimental results [12], HJC model [10] using literature value for material constants and K\&C model [11] 
to testify the accuracy of the proposed bi-axial model. As a result, bi-axial model proposed in this paper can be used to describe compressive bi-axial behaviour of concrete under high-strain rate conditions.

\section{Acknowledgements}

This research was supported by a grant from a Construction Technology Research Project (Development of impact/blast resistant HPFRCC and evaluation technique thereof) funded by the Ministry on Land, Infrastructure, Transport, the Defense Research Laboratory Program of the Defense Acquisition Program Administration and the Agency for Defense Development of Republic of Korea, Korea Minister of Ministry of Land, Transport and Maritime Affairs (MLTM) as U-City Master and Doctor Course Grant Program.

\section{References}

[1] Bischoff, P. and S. Perry, Compressive behaviour of concrete at high strain rates. Materials and structures, 1991. 24(6): pp. 425-450.

[2] S.T. Marais, R.B.T., T.J. Cloete \& G.N. Nurick, Material testing at high strain rate using the split Hopkinson pressure bar. Latin American Journal of Solids and Structures, 2004. 1(3): pp. 219-339.

[3] Georgin, J. and J. Reynouard, Modeling of structures subjected to impact: concrete behaviour under high strain rate. Cement and Concrete Composites, 2003. 25(1): pp. 131-143.

[4] Béton, C.e.-i.d., CEB-FIP Model Code 1990: Design Code. 1993.

[5] Hallquist, J.O., LS-DYNA keyword user's manual. Livermore Software Technology Corporation, 2007. 970.

[6] Hibbitt, Karlsson, and Sorensen, ABAQUS/Standard user's manual. Vol. 1. 2001: Hibbitt, Karlsson \& Sorensen.

[7] Bischoff, P. and S. Perry, Compressive strain rate effects of concrete. Cement-Based Composites: Strain Rate Effects on Fracture, 1986. 75(5): pp. 151-165.

[8] Malvar, L.J. and C.A. Ross, Review of strain rate effects for concrete in tension. ACI Materials Journal, 1998. 95(6): pp. 735-739.

[9] Bićanić, N. and O. Zienkiewicz, Constitutive model for concrete under dynamic loading. Earthquake Engineering \& Structural Dynamics, 1983. 11(5): pp. 689-710.

[10] Holmquist, T., G. Johnson and Cook W. A computational constitutive model for concrete subjected to large strains, high strain rate, and high pressures in 14th International Symposium on Ballistics. 1993.

[11] Schwer, L.E. and L.J. Malvar, Simplified concrete modeling with* MAT_CONCRETE_DAMAGE_REL3. JRI LS-Dyna User Week, 2005.

[12] Yan, D. and G. Lin, Dynamic behaviour of concrete in biaxial compression. Magazine of Concrete Research, 2007. 59(1): pp. 45-52. 